\title{
Major Dermatological Disorders of Carthorses in Selected Towns of Central Ethiopia
}

\section{Yidnekachew Tadesse ${ }^{2}$ and Fanos Tadesse Woldemariyam ${ }^{1^{*}}$}

${ }^{1}$ College of Veterinary Medicine and Agriculture, Addis Ababa University, Addis Ababa, Ethiopia

${ }^{2}$ Horo Guduru Zone Livestock and Fisheries Office, Ethiopia

\begin{abstract}
The study was conducted between November 2007 and June 2008 to provide base line information concerning causes and major skin disorders of carthorses in selected towns of Central Ethiopia. Physical clinical examination and laboratory tests were used in the Investigation. The overall prevalence of dermatological disorders in carthorses was found to be $93.3 \%$. This has no statistically significant difference ( $p>0.05)$ among the study sites. The major dermatological disorders identified were wounds $(67.2 \%)$, infectious skin diseases $(10 \%)$, tumor $(2.5 \%)$, ectoparasites $(7.3 \%)$ and mixed disorders $(6.4 \%)$. The majority of the horses $(82.6 \%)$ had dermatological disorders in more than one site. Laceration, erosion, puncture, avulsion, mixed and complicated wound types were identified. The major causes of wounds were improper harnessing, shoeing, beating, road accidents and multifactorial causes. Harness inflicted wounds were detected on lips, chest, back, girth and base of the tail. There was no statistically significant difference $(p>0.05)$ in the occurrence of harness related wounds among the study sites. The ectoparasites identified were louse $(2.7 \%)$, ticks $(4.7 \%)$ and mange mite $(1.78 \%)$. The infectious skin disorders detected in the study were dermatophilosis $(0.6 \%)$, dermatophytosis $(2.5 \%)$ and epizootic lymphangitis $(6.9 \%)$. Most of the skin disorders were afflicted by improper management of working horses. Education of cart owners on proper management with regular veterinary care was recommended to alleviate the prevailing dermatological disorders in the study sites. In addition, the infectious causes should be objectively researched.
\end{abstract}

Keywords: Carthorses; Central Ethiopia; Prevalence; Skin disorder

\section{Introduction}

There are about 115.2 million domestic equids (horses, donkey and mule) in the world of which 44.3 million are donkeys, 57.6 million horses and 13.3 million mules. Ethiopia shares approximately half of Africa's equine population; according to UN Food and Agriculture Organization there are over 7 million donkeys, mules and horses in Ethiopia, including 1.9 million horses [1]

In a country where there is less developed transport and communication services and road network insufficiently developed, the natural choice rests on the use of human labor and pack animals as a mode of transport, as it has been the case in some parts of the world. This remains true in the Ethiopian context. The mountainous nature of the land has made the travel time consuming and difficult, which has resulted the back of animals to remain as the only means of transport for Ethiopian terrain for centuries [2]. Horses have a prominent position in the agricultural systems as draft, pack and riding animals. In many towns of Ethiopia horse pulled carts are used as a major means of transportation and as a source of income for cart owners [3,4]. In other words, the use of equines in door to door transport service provides urban dwellers with the opportunity of income generation $[5,6]$.

Despite their invaluable contributions, equines in Ethiopia are the most neglected animals, accorded low social status, particularly the male working equines. Horses involved in pulling carts often work continuously for 6 to 7 hours per day, carrying 3 to 4 persons (195-260 $\mathrm{kg}$ ) in single trip [7]. They are provided with wheat bran and cereal straw by moistening with water and grasses where season provide on access during the night and allowed to graze pasture and road side in the town fringe during the day. Feed shortage and disease are the major constraints to the productivity and work performance of carthorses. They are brutally treated, made to work overtime without adequate feed or health care. The increasing human population, demand for transport of goods to and from far, remote areas, and construction activities around the town are making cart horses high demanded animal [8].

There are several causes of health problem in carthorses which are actively participating in the transport sector. The causes of this health problem emanates from infectious diseases, parasite infestation, mechanical damage, lack of adequate feed and some others. So the outcome that arises from these causes in combination or alone could affect the entire body systems or a single tissue, organ or system which has great impact on the performance expected from the animal. Of these dermatological (skin) problems is among the major ones.

Skin is the largest organ of the body which serves as an inclosing barrier and providing environmental protection, regulating temperature, providing pigment and vitamin $\mathrm{D}$, sensory perception, etc. Anatomically it consists of epidermis, basement membrane zone, dermis, appendageal system and subcutaneous muscles and fat. The skin is affected by a wide variety of diseases and reacts to disease in a limited number of ways. Thus, many diseases can appear similar and cause similar presenting signs yet have vastly different etiologies. Some skin diseases have predictable clinical features, whereas others can have a variety clinical forms.

*Corresponding author: Fanos Tadesse Woldemariyam, College of Veterinary Medicine and Agriculture, Addis Ababa University, Addis Ababa Ethiopia, Tel: +251912828253; E-mail: fanos.tadesse@aau.edu.et

Received December 26, 2016; Accepted January 20, 2017; Published January 25, 2017

Citation: Tadesse Y, Woldemariyam FT (2017) Major Dermatological Disorders of Carthorses in Selected Towns of Central Ethiopia. J Vet Sci Technol 8: 423. doi: 10.4172/2157-7579.1000423

Copyright: $\odot 2017$ Tadesse $Y$, et al. This is an open-access article distributed under the terms of the Creative Commons Attribution License, which permits unrestricted use, distribution, and reproduction in any medium, provided the original author and source are credited. 
In Ethiopia, though few reports indicated that external injuries and epizootic lymphangitis (Endebu, 1996; SPANA, 2003) are major health problems of working horses, there have been no formal researches conducted to elucidate general dermatological disorders of carthorses. Therefore, the objectives of this study were:

- To provide base line information concerning the major skin disorders of carthorses in selected districts of Ethiopia.

- To indicate factors influencing the occurrence and distribution of skin disorders of carthorses.

\section{Materials and Methods}

\section{Study area}

The study was conducted in three selected towns of central Ethiopia namely Debre Berhan, Debre Zeit, and Adama. These places were previously selected as working area by the mobile clinic of the society for the protection of Animals Abroad (SPANA) Ethiopia based on their high equine population, poor welfare condition and low economic status of carthorse owners. These areas were a working site of SPANA Ethiopia and believed to be vaccinated and dewormed.

Debre Brehan: It is a town located in Amhara Regional State, in the central highlands of Ethiopia, $130 \mathrm{~km}$ north east of Addis Ababa, at $9^{\circ} 36^{\prime} \mathrm{N}$ and $39^{\circ} 38^{\prime} \mathrm{E}$, with an altitude of 2780 meter above sea level. The average annual rainfall is $950 \mathrm{~mm}$ and the average monthly minimum and maximum air temperature ranges from $17.6^{\circ} \mathrm{C}$ in August to $22.5^{\circ} \mathrm{C}$ in June. The mean relative humidity is $68.2 \%$. There are 714 carthorses and 357 carts in the town [9].

Debre Zeit: The town is $45 \mathrm{~km}$ south east of Addis Ababa, located $9^{\circ} \mathrm{E}$ at an altitude of $1850 \mathrm{~m}$ above sea level. The rainfall is bimodal. It receives the annual rainfall of $1151.6 \mathrm{~mm}$ with a mean maximum and minimum temperature of $30.7^{\circ} \mathrm{C}$ and $8.5^{\circ} \mathrm{C}$ respectively, and a mean relative humidity of $61.3 \%$ [10]. There are 1170 carthorses and 585 carts in the town [11].

Adama: The town is located in Eastern shoa zone of Oromia Regional State, $100 \mathrm{~km}$ southeast of Addis Ababa at $8^{\circ} 32^{\prime} \mathrm{N}$ and $39^{\circ} 17^{\prime} \mathrm{E}$. It has an altitude of 1622 meter above sea level in the Great Rift Valley and receives annual rainfall ranging from $400 \mathrm{~mm}$ to $800 \mathrm{~mm}$ and a temperature of $13.9^{\circ} \mathrm{C}$ [10]. There are 1579 carthorses and 790 carts in the town [12].

In all the three sites the means of transportation include vehicle and horse drawn carts. Horse drawn carts are preferably used on roads inaccessible to taxi and because of relatively low charges. However, there is great competition between horse drawn carts and Bajaj (a three wheel motor bike).

\section{Target population and sampling strategy}

The total population of carthorses in the present study areas was 3423. Simple random sampling method was employed on each study sites irrespective of owner's primary complaint, age, body condition score, coat color

and/or any other parameters of horses. Discussion was made with the owners to know about the causes of dermatological disorder in their respective areas.

\section{Sample size determination}

The sample size was determined according to Thrusfield [13]. Simple random sampling for an infinite population with 95\% confidence level, $5 \%$ derived absolute precision and $50 \%$ expected prevalence, since there was no previous information on the prevalence of major skin disorders in present study areas. Accordingly, 74 horses in Debre Brehan, 123 horses in Debre Zeit and 163 horses in Adama were selected.

$$
\begin{aligned}
& n=\underline{1.96}-\underline{\exp (1-P \exp )} \\
& d^{2} \\
& N a d j=\underline{N x n} \\
& N+n \\
& \text { Nadj : adjacent population } \\
& N: \text { required sample size } \\
& P: \text { prevalence } \\
& d: \text { desired absolute precision }
\end{aligned}
$$$$
\text { Pexp: expected prevalence }
$$

\section{Study methodology}

Physical examination of skin: Physical examination of skin included inspection at a distance to get general idea of the distribution and the extent of the disease. Then the skin was closely examined by sight and touch. Examination was undertaken from cranial to caudal body parts; from the head region to the tail including mucous membranes and mucoutaneous junctions. Age, body condition score, skin elasticity, skin thickness, type of hair coat, type and cause of dermatological disorders and body sites affected were recorded for all horses in each site.

Laboratory examination: Laboratory examination was employed where infectious and parasitic disorders were suspected during physical examination. Samples were taken by skin scrapings, hair plucking, collection of crusts and pus material from abscessed parts. Then, the samples were labeled and laboratory results for isolation of causative agents in cases where necessary were recorded.

Data analysis: The collected data were entered to computer using excel soft ware data. Data were listed in a format i.e., rows for horses identification number and sites of study, and columns for physical and laboratory examination results. SPSS 13.0 for windows was used to analyze the descriptive statistics. In the analysis confidence level was held at $95 \%$ and $\mathrm{P}<0.05$ was set for significance.

\section{Results}

\section{Physical and laboratory examination}

The overall prevalence rate of dermatological disorder in the study sites was $93.3 \%$ (Table 1). Up on physical and laboratory examination wounds (67.7\%), infectious diseases (10\%), parasitic infestations (7.2\%), skin tumor (2.5\%) and other disorders (6.4\%) were found among the major dermatological disorder of horses in the study site (Table 2). About $82.6 \%$ of the horses had dermatological disorders in more than one site (Table 3 ). There was no statistically significant difference in

\begin{tabular}{|c|c|c|}
\hline Study site & Count & Percentage \\
\hline DebreBrehan & 67 & $90.50 \%$ \\
\hline DebreZeit & 117 & $95.10 \%$ \\
\hline Adama & 152 & $93.30 \%$ \\
\hline Total & 336 & $93.30 \%$ \\
\hline
\end{tabular}

Table 1: Overall prevalence of dermatological disorder in study sites. 
Citation: Tadesse Y, Woldemariyam FT (2017) Major Dermatological Disorders of Carthorses in Selected Towns of Central Ethiopia. J Vet Sci Technol 8: 423. doi: 10.4172/2157-7579.1000423

Page 3 of 4

\begin{tabular}{|c|c|}
\hline Dermatological disorders & Percentage \\
\hline Wounds & $242(67.7 \%)$ \\
\hline Infectious diseases & $36(10 \%)$ \\
\hline Parasitic infestations & $26(7.2 \%)$ \\
\hline Skin tumor & $9(2.5 \%)$ \\
\hline Other skin disorders & $23(6.4 \%)$ \\
\hline
\end{tabular}

Table 2: Type of dermatological disorders identified in the study sites.

\begin{tabular}{|c|c|c|c|c|}
\hline Study site & \multicolumn{3}{|c|}{ Number of body sites affected } \\
\hline & One body site (\%) & Two body sites (\%) & Multiple body sites (\%) & Total (\%) \\
\hline Debre Brehan & $16(23.88 \%)$ & $23(34.32 \%)$ & $67(19.79 \%)$ \\
\hline Debre Ziet & $22(18.8 \%)$ & $32(27.35 \%)$ & $63(53.84 \%)$ \\
\hline Adama & 23(15.03\%) & $36(23.68 \%)$ & $93(61.18 \%)$ \\
\hline Total & $\mathbf{6 1 ( 1 8 . 1 5 \% )}$ & $\mathbf{9 1 ( 2 7 . 0 8 \% )}$ & $\mathbf{1 8 4 ( 5 4 . 7 6 \% )}$ \\
\hline
\end{tabular}

Table 3: Distribution of dermatological disorders on body parts.

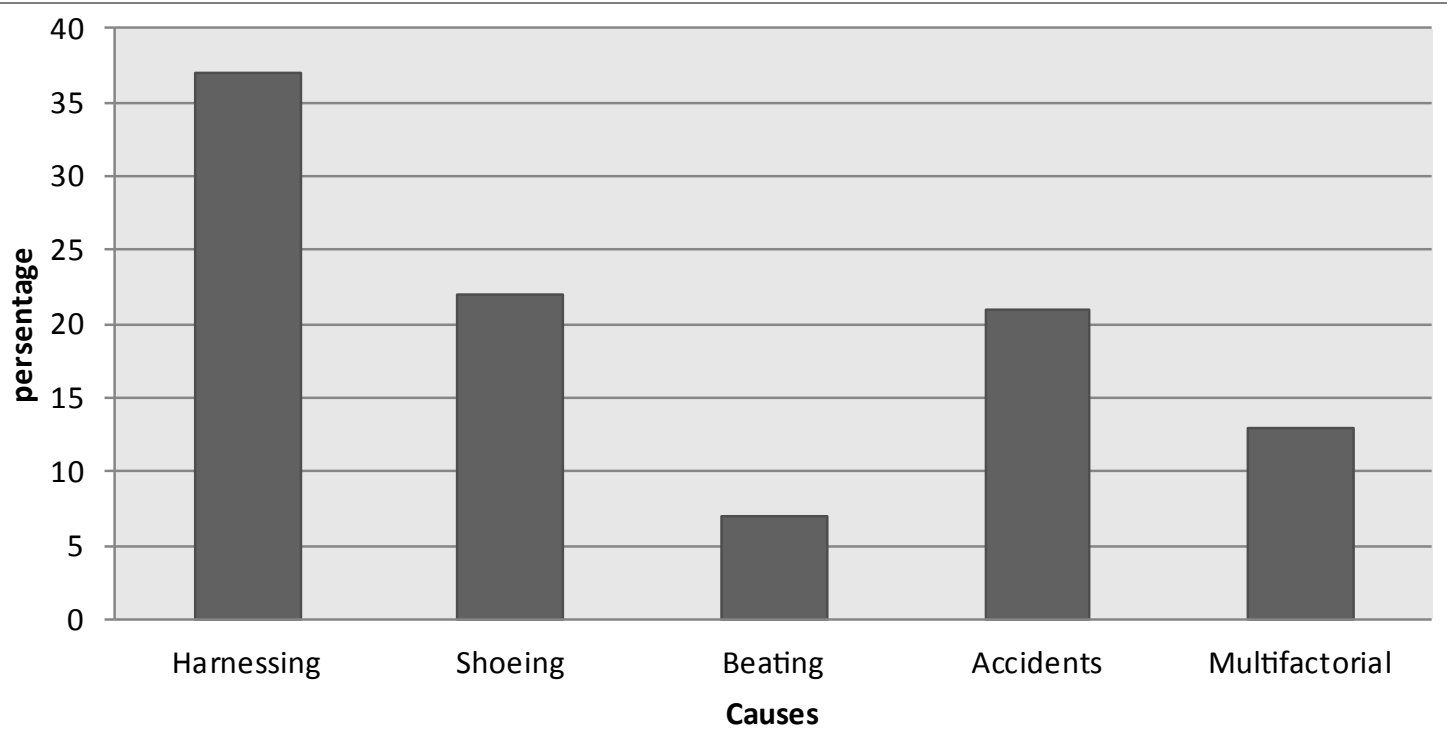

Figure 1: Major causes of wounds identified in the study sites.

\begin{tabular}{|c|c|c|c|c|c|c|c|}
\hline \multirow{2}{*}{ Study site } & \multicolumn{7}{|c|}{ Wound type } \\
\hline & Erosion & Puncture & Laceration & Avulsion & Mixed & Complicated & Total \\
\hline Debre- Berhan & $0(0.0 \%)$ & $7(15.9 \%)$ & $17(38.6 \%)$ & $1(2.3 \%)$ & $10(22.7)$ & $9(20.5 \%)$ & $44(100 \%)$ \\
\hline Debre- Zeit & $1(1.1 \%)$ & $29(31.87 \%)$ & $28(30.8 \%)$ & $4(4.4 \%)$ & $15(16.48)$ & $14(15.4 \%)$ & $91(100 \%)$ \\
\hline Adama & $5(4.67 \%)$ & $15(14.02 \%)$ & $47(43.3 \%)$ & $4(3.47 \%)$ & $20(18.69 \%)$ & $16(14.95 \%)$ & $107(100 \%)$ \\
\hline Total & $6(2.48 \%)$ & $51(21.07 \%)$ & $92(38 \%)$ & $9(3.72 \%)$ & $45(18.6 \%)$ & $39(16.1 \%)$ & $242(100 \%)$ \\
\hline
\end{tabular}

Table 4: Type of wounds identified in the study sites.

the prevalence rate and type of disorders identified with respect to the study sites as well as the body parts affected by dermatological disorder ( $>>0.05)$.

The type of wounds identified were Laceration, erosion, puncture, avulsion, mixed and complicated wound types where Laceration and puncture takes about $60 \%$ of the share of wounds type in the three study sites (Table 4). The major causes of wounds were improper harnessing, shoeing, beating, road accidents and multifactorial causes (a combination of improper harnessing, shoeing, beating and road accident) (Figure 1).

\section{Discussion}

In the present study it is showed that the extremely high prevalence different types of dermatological disorders in carthorses with multiple body part appearance taking the largest share. The overall prevalence dermatological disorder in carthorses was found to be $93.3 \%$ which is in agreement with the finding of Biffa and Woldemeskel; Demsasha and Denka in different parts of Ethiopia [7,14]. The major dermatological disorders identified were wounds, infections skin diseases, tumor and 
ecto-parasites. Of these disorders wounds took the largest share (67.7\%) of the dermatological disorders in the study site. This finding clearly indicated the magnitude of the problem in working horses. These dermatological disorders inevitably decrease the performance and effective working life of horses. This is comparable with the findings of Tamirat et al. (58.6\%) in Wolaita Soddo and Abreha et al (30.3\%) in Tigray which showed wounds are the major dermatological problems followed by infectious skin diseases, tumor and ecto-parasites $[15,16]$.

The majority of the wounds identified were severe type where a wide area of the skin were removed. Most of these wound that affect the skin of the horses were due to mis-management and ill treatment of horses where poorly fitted harness with rigid and rough edges, improper shoeing and beating were the prevailing mal-practice in all the study sites. This is in agreement with the findings of Tamirat et al. and Abreha et al. in wolaita and Tigray, Ethiopa $[15,16]$. Our finding agrees with explanation of Pearson and her colleagues who stated that harness related problems were raised from incorrect size, inappropriate fitness, too narrow or too thin, made of unsuitable synthetic materials, poor paddle, poor design and synthetic rope to tried be fitted to the animal.

The dermatological disorders were found in one, two or multiple body parts of the horses in three study areas where the multiple body part occurrence was in higher proportion (54.76\%) similar to our finding Biffa and Woldemeskel also found the multiple occurrence of wounds in different equine species.

\section{Conclusions and Recommendation}

The present study revealed higher prevalence of dermatological disorders in cart horses of the study sites. The major disorders were wounds, ecto-parasites, infectious skin diseases and tumors. Most of the wounds were afflicted by improper management of working horses. Based on the above concluding remark the following points are forwarded:

- There should be better or modern utilization harnessing system in carthorses

- Appropriate management system should develop in order to avoid the occurrence of wound.

- Develop regular deworming programme towards the control of ectoparasites.

- The infectious cases should be objectively researched.

- Develop better skill or awareness of animal welfare towards cart owners and drivers.

\section{References}

1. ANON (2010) FAOSTAT. FAO Statistics Division. Accessed January 13, 2017.

2. Hassen K (2000) Preliminary Study on socio- economic importance, Health
Problems and other Management Constraints Horse in Mid and Highland area of North Gonder. DVM Thesis. FVM, AAU, Debre-Zeit, Ethiopia.

3. Endebu B (1996) Epidemiology of Epizootic Lymphangitis in Ethiopia. Retrospective Analysis, Cross Sectional Study and Treatment Trial at DebreZeit and Akaki Towns. DVM Thesis. FVM, AAU, Debre-Zeit, Ethiopia.

4. SPANA Ethiopia, Consultant Document (2003) Welfare of Carthorses Baseline Survey. Society for the Protection of Animals Abroad (SPANA) Ethiopia.

5. Wilson RT (1991) Equine in Ethiopia. In: Fielding D, Pearson RA (eds.) Donkey, Mule and Horse in Tropical Agricultural Development Proceeding Colloquium Held 3-6 September 1990. Centre for Tropical Veterinary Medicine, University of Edinburgh, Scotland, pp: 33-47.

6. Agajie T, Tamirat D, Pearson A, Temesgen T (2000) Socio-economic circumstances of Donkeys, Use and Management in the Rural and Urban Areas of Central Part of Ethiopia. Proceedings of the workshop on promoting the peri-urban livelihood through better donkey welfare. Debrezeit, Ethiopia pp: $16-28$.

7. Biffa D, Woldemeskel M (2006) Causes and Factors Associated with Occurrence of External injuries in working equines in Ethiopia. Intern J Appl Rev Vet Med 4: 1-4.

8. Mengistu A (2003) The Genetic Resources Perspective of Equines in Ethiopia and their contribution to the Rural Livelihood. Proceedings of the $11^{\text {th }}$ annual conference of Ethiopia society of animal production (ESAP). Addis Ababa, Ethiopia, pp: 18-85.

9. Debre-brehan Municipality (2007) Debre-brehan Municipality (Office). Unpublished.

10. NMSA (2000) National Metrology Service Agency. Addis Ababa, Ethiopia.

11. DebreZeit Municipality (2007) DebreZeit Municipality (Office), Unpublished.

12. Adama Municipality (2007) Adama Municipality (Office), Unpublished.

13. Thrusfield M (1995) Veterinary Epidemiology. 3rd edn. Black Well Publishing, p: 339.

14. Demsasha T, Tamiru BD (2015) Injuries are the Predominant Cause of Deviation in the Health of Working Equines in and Around Gondar Town, North West Ethiopia. External J Vet Adv 5: 1071-1078.

15. Tamirat H, Mulisa M, Ayalew N, Teka F (2015) Assessment on Working Donkey Welfare Issue in Wolaita Soddo Zuria District, Southern Ethiopia. Global Veterinaria 14: 867-875.

16. Abreha T, Yohannes T, Habtamu T, Kalab G, Hagos $Y$ (2015) Survey of Common Skin Problem of Working Equines in and Around Mekelle, North Ethiopia. Acad J Anim Dis 4: 30-38. 